\title{
Capturing Micro-Expressions on Zoom: A Promising Sales Opportunity
}

\author{
Oscar McKnight \\ Ashland University \\ Chris Mahar \\ Ashland University \\ Ronald Paugh \\ Ashland University \\ Jonathan Meredith \\ Ashland University \\ Josiah Moore \\ Ashland University
}

The subtleties of salesmanship are changing in this virtual world of online communication. This proof-ofconcept study examines the feasibility of capturing customer images at the two, ten, and thirty-second intervals following a Zoom platform's sales query. A captured image underwent a micro-expression analysis employing a computer-driven program that generates an emotional-algorithm analyzing the emotions of happy, neutral, sad, disgust, fear, surprise, and anger. This algorithm enabled researchers to predict a purchase-decision using proprietary artificial intelligence software. Findings suggest that microexpressions captured at the two-second interval exhibited a significant relationship with a customer's purchase decision. A summary table provides a detailed overview of all results using the acronym [MICRO].

Keywords: sales, virtual calls, micro expressions, sales generation, cold calling, video conferencing, artificial intelligence

\section{INTRODUCTION}

The subtleties of salesmanship are ever-changing in this new virtual world. Physical face-to-face communication is declining as technology use increases, for example, using video conferencing (Drago, 2015). Today, the sales professional must be astutely aware of the physical customer and the virtual one. As a result, virtual online sales approaches share numerous similarities with the cold call. Moreover, with the advent of LinkedIn, Twitter, Instagram, and Facebook, purchasing verified customer lists (Oldroyd, 
McElheran \& Elkington, 2011), sales calling and cold calling should improve. However, securing such verified lists (by location and email) may be more an act of quiet desperation than a proven business practice, given the historical customer response rate of $1 \%$ to $2 \%$, which by comparison is the lowest response or conversion rate of other marketing activities (Taylor, 2010). Yet, conversion rates vary according to industry and product, but most online sales, that is, sixty-two percent, have conversion rates between $1 \%$ and $9 \%$ (Zumstein and Kotowski, 2020). When analyzing qualification checklists, Banerjee and Bhardwaj (2019) reported that these names of interest often use minimum criteria.

However, Banerjee and Bhardwaj (2019) did clarify that purchasing [lead qualification services] from marketers with more intimate customer knowledge is valuable for sales professionals, especially when a deal's uncertainty is high and sales commissions are sizable and integral to total remuneration. The researchers stress that lead qualification can be an arduous and expensive process but is necessary. Hence, it warrants developing paradigmatic and heuristic strategies that enhance any deemed qualified lead's predictive validity.

Today, many sales professionals, irrespective of their source of sales leads, employ virtual video conferencing platforms to conduct cold calls, presentations, and sales meetings. For example, Zoom has reported 300 million users per day as of April 2020, up from 10 million in December 2019 (Warren 2020). This outcome parallels significant expansions in users for Microsoft Teams and Google Meet, demonstrating increasing support for virtual business (Warren 2020). Likewise, Ali (2021), when analyzing the US. Department of Commerce data found that the online share of total retail sales is up 21.3 percent and pointed out that online sales were $15.8 \%$ in 2019 and $14.3 \%$ in 2018.

Now more than ever, a more perceptive understanding of nonverbal communication in the virtual sales call is essential. The contemporary and sophisticated sales professional requires a technique that resonates with a prospective client via the internet's virtual capabilities. Moreover, there is a need to yield an estimate of the probability of a positive purchase-decision elicited by any non-verbal behavior, specifically facial, given the aforementioned mentioned use of online sales platforms. However, facial expressions are fleeting and potentially unnoticed in traditional human visual processing.

\section{LITERATURE REVIEW}

Customers express their emotions using verbal and nonverbal cues in numerous ways. Body language is a popular topic and discussed in the academic literature since the 1960s (see Argyle 1969; Duncan,1969; and Knapp, 1972). These researchers investigated the importance of recognizing body contact, posture, physical appearance, gaze, and the individual's tone of voice as an indication of thought. Yet, it is common knowledge that individuals tend to feign, hide, distort, or even exaggerate emotions with guided intention. Still, spontaneous facial expressions endure for seconds, and an individual is hard-pressed to conceal them (Wezowski and Wezowski, 2012). Porter and ten Brinke (2008) explain how these spontaneous facial expressions are really [thought] micro-expressions conveying a plethora of personal information. In the 1960s, Haggard and Isaacs (1966) coined the phrase [micromomentary expressions], which today are micro-expressions. Ekman, in 2003 operationalized micro-expressions as involuntary facial expressions that occur within a fraction of a second and exposes a person's genuine emotions. Thus, it is reasonable to assume that purchase decisions can carry an emotional charge, often embedded in an individual's face as micro-expressions. As Beheshti (2018) postulated, unconscious expressions do more than reinforce our conscious conversation; sometimes, the micro-expressions are the conversation.

A systematic and comprehensive review of research in the business and psychology journals revealed no relevant research utilizing an algorithm-driven model examining the relationship between facial microexpression and purchasing behavior. However, Afifi (2007) emphasized that characterizing nonverbal communication solely as body language ignores several essential elements and the meaning of microbehaviors within their social or cultural setting. For example, McKnight et al. (2020) found a significant relationship between students' facial ID micro-expressions and college retention probability. Moreover, Kolb and Williams (2003) researched the role of micro-expressions as a hidden context in negotiations. 
However, there is no published research examining micro-expressions and consumer purchase decisions discovered for this research. Nevertheless, this topic is worthy of investigation, given the minuscule return on cold calling reported by Taylor (2010). Also, recognizing that sales professionals often do not possess sufficient time to pursue seventy percent of all prospective customers on any purchased or generated sales list (Sabnis et al., 2013). Given these challenges, the sophisticated sales professional must possess an efficient and effective way to triage high sales-probability customers.

\section{QUESTIONS OF INTEREST}

There is research examining the sales influence of what the customer perceives in relationship to the salesperson's image, including positive customer perceptions for virtual sales assistants (Beldad, Hegner, \& Hoppen, 2016) and avatars (Bauer et al., 2006). However, this research redefines image analysis by focusing on prospective customers' micro-expressions and their influence on anticipated purchase-decision. Therefore, the image of importance to this research is the potential customer, not any live or virtual sales professional or avatar. As such, this is a proof-of-concept study to explore the possible or theoretical use of micro-expression analysis within sales. Therefore, given this exploratory proof-of-concept research, one fundamental research question is separated into two discrete parts.

1. Is there a significant relationship between a captured micro-expression and an individual purchase decision at the (two, ten, thirty) second interval?

2. Will statistical findings support the feasibility of implementing image analysis, by microexpression, into the online virtual sales process?

\section{METHODOLOGY}

Two focus groups of twelve participants and three alternates $(\mathrm{N}=27)$ matched closely with national demographics to age (median $=55$ yrs. old), race $(14 \%$ minority), and education $(\mathrm{HS}=80 \%)$ agreed to participate in a Zoom meeting discussing an active legal case's dynamics. However, before their legal case participation, all previously agreed to engage in one collaborative virtual Zoom group and respond to six "icebreaker" questions not related to the legal case. All members, by participation, knowingly and willingly consented to video recording.

Before participation, each individual received a Google survey allowing them to respond [YES] or [NO] to six questions in the privacy of their home during the video call. This format prevented consensus groupthink by eliminating public disclosure of answers. There were no written questions on the form, but an answer key recording initial non-verbal responses in real-time. The six questions originated from a random selection of twenty, written by three practicing sales and marketing professionals. The intent was to select a variety of sales environments to assess generalizability.

Each question posed during videotaping allotted a one-minute response time, followed by another question. The video analysis included freezing video frames at the two, ten, and thirty-second intervals upon completing the six questions. At each interval, the researchers captured a still frame image of the Zoom meeting. This time frame image became the focal point of micro-expression analysis, with most captured images occurring within 1.5 seconds of the maximum target time. The adjustment reflects the time required to secure a clear picture.

Micro-expression analysis transpired using a facial-feature recognition program utilizing ten thousand faces in a machine learning model. This analytic process is a form of artificial intelligence (AI) that, through "training," recognized the probability of seven expressed emotional states: Happy, Neutral, Sad, Disgust, Fear, Surprise, and Anger.

Each image, by timeframe and question, underwent analysis by sentiment breakdown. The computer

program allowed for controlling human researcher bias because an algorithm scored all emotions. For clarification, the program utilizes OpenCV to perform facial recognition and incorporates a Convolutional Neural Network $(\mathrm{CNN})$, trained on a modified version of the FerPlus emotion dataset from Microsoft. 
The image has adjustments applied to it (such as brightness, rotation, etc.) before the CNN processes an image. The CNN then ascertains appropriate emotions expressed. The program assigns a probability rating regarding the highest emotion expressed on a one-hundred-point scale, with $1=$ lowest probability and $100=$ highest probability, then rank-orders the other six emotions into an algorithm for a predictive purpose (see Figure 1).

\section{FIGURE 1 \\ HYPOTHETICAL IMAGE ANALYSIS OF MICRO-EXPRESSIONS}

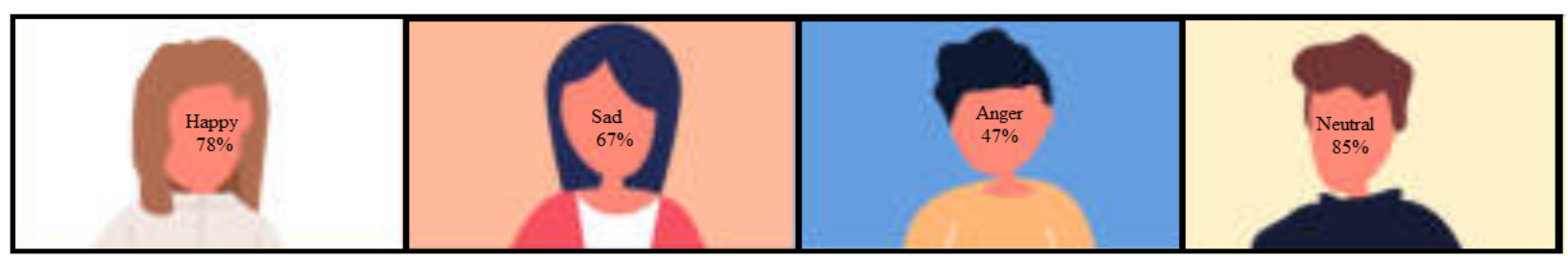

Note. For clarification, image analysis may not detect a micro-expression, or the participant may not be using their camera.

Each image (potential customer) and their assessed micro-expression algorithm came with an artificial weight assigned by the program to create a rank-order. All images maintained the same assigned weights throughout the process for consistency and standardization of the rank-order of the probabilities associated with the detected micro-expression. Happiness possessed the highest weight and Anger the lowest, as noted in Figure 1.

Researchers correlated the resulting rank-order of micro-expressions by the question and time-sequence with the participant's decision to purchase or not purchase. The sales queries were:

Q1. Do you think that you may buy a Lotto Ticket sometime this year?

Q2. Do you think that you would support a new tax levy for Child Protective Services?

Q3. Do you think that you will buy more than one bottle of vitamins this year?

Q4. Do you think that you will pay for the services of a financial planner in the future?

Q5. Do you think that you may purchase a drone camera at some point in the future?

Q6. Do you think that you will purchase a new coat this year?

\section{RESULTS}

The fundamental research question examined if there was a significant relationship between a Zoomcaptured micro-expression and an individual's purchase-decision at the two, ten, and thirty-second intervals.

In the first query, [Do you think that you may buy a Lotto Ticket sometime this year?] findings indicate a significant correlation coefficient of .74 with a probability level of $<.0001$. The highest emotional microexpression was Happy. This was a significant positive correlation between the expression and the purchase decision at the two-second interval. However, the ten and thirty-second micro-expressions could not predict the purchase-decision.

In the second query, [Do you think that you would support a new tax levy for Child Protective Services?] findings indicate a significant correlation coefficient of -.46 with a probability level of $<.03$. The highest emotional micro-expression was Sad. This was a significant negative correlation between the 
expression and the purchase decision at the two-second interval. The ten and thirty-second microexpressions were not significant.

In the third query, [Do you think that you will buy more than one bottle of vitamins this year?] findings indicate a significant correlation coefficient of .57 with a probability level of $<.007$. The highest emotional micro-expression was Neutral. This was a significant positive correlation between the expression and the purchase decision at the two-second interval. The ten and thirty-second micro-expressions were not significant.

In the fourth query, [Do you think that you will pay for the services of a financial planner in the future?] researchers found no significant correlation between the micro-expression and purchase decision at any of the two, ten, and thirty-second intervals. The highest emotional micro-expression was Neutral.

In the fifth query, [Do you think that you may purchase a drone camera at some point in the future?] findings indicate a significant correlation coefficient of -.48 with a probability level of $<.05$. The highest emotional micro-expression was Anger. This was a significant negative correlation between the expression and the purchase decision at the two-second interval. The ten and thirty-second micro-expressions were not significant.

In the sixth query, [Do you think that you will purchase a new coat this year?] findings indicate a significant correlation coefficient of .47 with a probability level of $<.05$. The highest emotional microexpression was Happy. This was a significant positive correlation between the expression and the purchase decision at the two-second interval. The ten and thirty-second micro-expressions were not significant.

There was an evocative anecdotal finding in eleven of the twelve sales queries when the participants did not activate their camera; their response was [NO]. The probability of this [NO] response occurring by chance is .006 utilizing binomial analysis, two-tail test. However, with no detection of the micro-expression, of the twenty-five, a [NO] response occurred ten times. The probability of this finding is 0.42 utilizing binomial analysis, two-tail test. For a complete summary of results and a validation summary, see Tables 1 and 2 .

TABLE 1 SUMMARY OF FINDINGS; QUERIES 1 - 6

\begin{tabular}{|c|c|c|c|c|c|c|c|}
\hline Question & $\begin{array}{c}2 \\
\text { seconds }\end{array}$ & $\begin{array}{c}10 \\
\text { seconds }\end{array}$ & $\begin{array}{c}30 \\
\text { seconds }\end{array}$ & $\begin{array}{c}\text { Base } \\
\text { Emotion }\end{array}$ & $\begin{array}{c}\text { N-Size } \\
(27)\end{array}$ & $\begin{array}{c}\text { No } \\
\text { Detection }\end{array}$ & $\begin{array}{c}\text { No } \\
\text { Camera }\end{array}$ \\
\hline Q1 & $0.74 * * * *$ & 0.08 & -0.17 & Happy & $n=20$ & $\mathrm{n}=5$ & $\mathrm{n}=2$ \\
\hline Q2 & $-0.46 * *$ & -0.14 & 0.15 & Sad & $n=22$ & $\mathrm{n}=3$ & $\mathrm{n}=2$ \\
\hline Q3 & $0.57 * * *$ & 0.17 & 0.02 & Neutral & $n=21$ & $n=4$ & $n=2$ \\
\hline Q4 & 0.1 & -0.03 & -0.13 & Neutral & $n=23$ & $n=2$ & $n=2$ \\
\hline Q5 & $-0.48^{*}$ & 0.12 & -0.12 & Anger & $\mathrm{n}=17$ & $\mathrm{n}=8$ & $\mathrm{n}=2$ \\
\hline Q6 & $0.47 *$ & -0.06 & 0.17 & Happy & $n=22$ & $n=3$ & $n=2$ \\
\hline Mean & 0.47 & 0.10 & 0.13 & $\begin{array}{c}4 \text { of } 7 \\
\text { emotions }\end{array}$ & $\begin{array}{c}125 \text { of } \\
162\end{array}$ & 25 of 162 & 12 of 162 \\
\hline \multicolumn{8}{|c|}{$<007 * * *$} \\
\hline
\end{tabular}

TABLE 2

VALIDATION SUMMARY: HIT-RATIO

\begin{tabular}{|c|c|c|c|c|c|c|c|c|}
\hline \multicolumn{10}{|c|}{ Hit-Ratio: Validation Table } \\
\hline Variable & Q1 & Q2 & Q3 & Q4* & Q5 & Q6 & Hit-Ration 1 & Hit-Ration 2 \\
\hline Hit-Ratio: Yes Purchase & 0.82 & 0.67 & 0.71 & 0.00 & 0.71 & 0.67 & 0.60 & 0.72 \\
\hline Hit-Ratio: No Purchase & 0.78 & 0.85 & 0.86 & 1.00 & 0.80 & 0.60 & 0.82 & 0.78 \\
\hline Mean Hit-Ratio & 0.80 & 0.77 & 0.81 & 0.50 & 0.76 & 0.64 & 0.71 & 0.76 \\
\hline \multicolumn{10}{|c|}{ *Question 4: } \\
\hline
\end{tabular}

Note. Hit-Ratio 1 includes non-significant findings of Q4. Hit-Ratio 2 excludes non-significant results of Q4. 


\title{
DISCUSSION AND IMPLICATIONS
}

This research indicates in five of the six queries, individual micro-expressions taken at the two-second interval could successfully differentiate between a YES or NO purchase-decision. However, as time progressed, recorded micro-expressions could not reflect a negative or positive purchase-decision, strengthening the supposition that micro-expressions reflect unconscious and visceral responses. It is also important to note that the Base Emotion (highest probable emotion expressed) was not consistent regarding the expressed purchase-decision. This finding suggests that a researcher cannot assume one specified emotion will consistently exhibit a significant relationship with the purchase-decision.

This research reveals that it is possible to create a sales database of images reflecting a prospective customer's micro-expressions. This micro-expression database would empower a sales professional to run a series of designed tests to identify a significant algorithm predicting a purchase-decision. Findings further indicate an overall accuracy of purchase-decision to be $76 \%$ when examining statistically significant results. The benefit of such an analysis or test series is that it would enable the sales professional to identify highprobability purchasers in a virtual sales presentation. Moreover, micro-expressions' historical sales data could help prioritize cold calls using existing photos of potential clients (See McKnight et al., 2020).

The use of video conferencing or online sales calls is increasing. Consequently, it will become a strategic imperative to explore the potential use of micro-expression analysis online and virtually as a basis for segmenting and prioritizing prospective and current customers. Not only will the process be selfvalidating, but a professional and empowered sales team equipped with a revolutionary technique will likely result in a more enlightened, efficient, and lucrative approach to segmenting and prioritizing sales leads (Sabnis et al., 2013). Moreover, the ability to communicate the effectiveness of facial micro-expression analysis across industries will reduce the relative inefficiency of focusing on sales leads with a low probability of purchase.

Researchers acknowledge that organizations can spend inordinately on lead generation, viz., $15 \%$ of gross target revenue or more (B2B Growth Agents, 2020). The use of software to analyze and prequalify leads can significantly reduce the cost, time, and human resources necessary to achieve a degree of certainty that is much more predictable than self-reporting measures.

As technology, machine learning, and AI grow, their ongoing usefulness in professional sales will also increase. Table 3 summarizes findings using the acronym MICRO.

TABLE 3

\section{MICRO: A PROMISING SALES OPPORTUNITY}

\author{
Micro-expressions predict purchase behavior \\ Intervals of time are essential in predictive algorithms \\ Conscious deception is difficult given minute timeframes \\ Recording meetings enables the measurement of micro-expressions \\ Online virtual salespeople will benefit from micro-expression analysis tools
}

\section{LIMITATIONS AND FUTURE RESEARCH}

This research highlighted several thought-provoking findings and implications; however, researchers convened a convenience sample consisting of two nationally normed focus groups gathered to discuss a pending legal case. The researchers were unable to design or select participants. Moreover, the sample size was relatively small. Therefore, the generalization of results without further replication is tenuous.

Other potential limitations exist with the process. For example, although videotaping the virtual group meetings mitigated the problem of standardizing the timeframes employed, researchers could not control if the participants had activated their camera or if the program would always detect the micro-expressions exhibited. This inability to detect the micro-expression occurred because of blurred images or facial positioning. 
Given the limitations mentioned above, this proof-of-concept study warrants a closer examination of customer micro-expressions in the future. For example, sales managers may utilize available and posed public images (e.g., LinkedIn) to assess future leads and sales calls. The exploration of base emotions (highest expressed probability) across industries, products, services, and customer typologies vis-à-vis a purchase-decision may indeed be a promising sales opportunity.

\section{REFERENCES}

Afifi, W.A. (2007). Nonverbal Communication. In B.B. Whaley \& W. Samter (Eds.), Explaining communication: Contemporary theories and exemplars (pp. 39-60). Lawrence Erlbaum Associates Publishers.

Ali, F. (2021, January 29). US eCommerce grows 44.0\% in 2020. Digital Commerce 360. Retrieved from https://www.digitalcommerce360.com/article/us-ecommerce-sales/

Argyle, M. (1969). Social interaction. New York, NY: Atherton.

B2B Growth Agents. (2020). How much should you spend on lead generation? Retrieved from https://info.mezzaninegrowth.com/blog/the-just-right-lead-generation-budget

Banerjee, S., \& Bhardwaj, P. (2019). Aligning marketing and sales in multi-channel marketing: Compensation design for online lead generation and offline sales conversion. Journal of Business Research, 105, 293-305.

Bauer, H., Neumann, M., Haber, T., \& Mader, R. (2006, Winter). Virtual sales agents. American Marketing Association, pp. 226-231.

Beheshti, N. (2018, September 20). The power of mindful nonverbal communication. Forbes Magazine. Retrieved from https://www.forbes.com/sites/nazbeheshti/2018/09/20/beyond-language-thepower-of-mindful-nonverbal-communication/?sh=b25097115018

Beldad, A., Hegner, S., \& Hoppen, J. (2016, July). The effect of virtual sales agent (VSA) gender product gender congruence on product advice credibility, trust in VSA and online vendor, and purchase intention. Computers in Human Behavior, 60, 62-72.

Drago, E. (2015). The Effect of Technology on Face-to-Face Communication. Elon Journal of Undergraduate Research in Communications, 6(1). Retrieved from http://www.inquiriesjournal.com/a?id=1137

Duncan, S.D., Jr. (1969). Nonverbal communication. Psychological Bulletin, 72, 118.

Ekman, P. (2003). Emotions revealed: Recognizing faces and feelings to improve communication and emotional life. New York: Times Books (Henry Holt and Co.).

Haggard, E.A., \& Isaacs, K.S. (1966). Micromomentary facial expressions as indicators of ego mechanisms in psychotherapy. In L.A. Gottschalk \& A.H. Auerbach (Eds.), Methods of research in psychotherapy (pp. 154-165). New York: Appleton Century Crofts.

Knapp, M.L. (1972). The field of nonverbal communication: An overview. In C.J. Stewart \& B. Kendall (Eds.), On speech communication: An anthology of contemporary writings and messages (pp. 5772). New York, NY: Holt, Rinehart \& Winston.

Kolb, D., \& Williams, J. (2003). Everyday negotiation: Navigating the hidden agendas of bargaining. San Francisco: Jossey-Bass.

McKnight, O., Mahar, C., Paugh, R., Meredith, J., \& Moore, J. (2020). Consumer behavior and image analysis: A student customer retention model. Journal of Marketing Development and Competitiveness, 14(3), 59-66. ISSN: 2155-2843

Oldroyd, J.B., McElheran, K., \& Elkington, D. (2011, March). The Short Life of Online Sales Leads. Harvard Business Review, 89(3).

Porter, S., \& ten Brinke, L. (2008). Reading between the lies: Identifying concealed and falsified emotions in universal facial expressions. Psychological Science, 19(5), 508-514.

Sabnis, G., Chatterjee, S.C., Grewal, R., \& Lilien, G.L. (2013). The sales lead black hole: On sales reps' follow-up of marketing leads. Journal of Marketing, 77(1), 52-67. 
Taylor, C.R. (2010). Attitudes toward direct marketing and its regulation. Journal of Public Policy and Marketing, 19, 228-237.

Warren, T. (2020, April 29). Microsoft Teams jumps 70 percent to 75 million daily active users. The Verge. Retrieved from https://www.theverge.com/2020/4/29/21241972/microsoft-teams-75million-daily-active-users-stats

Wezowski, K., \& Wezowski, P. (2012). The micro expressions book for business. Antwerp: New Vision.

Zumstein, D., \& Kotowski, W. (2020). Success factors of e-commerce: Drivers of the conversion rate and basket value. Proceedings of the 18th International Conference e-Society 2020, pp. 43-50. ISBN: 978-989-8704-14-6. Retrieved from https://www.researchgate.net/profile/Darius_Zumstein2/publication/340417892_ 